Article

\title{
Third-Body and Dissipation Energy in Green Tribology Film
}

\author{
Shih-Chen Shi *(D) and Shia-Seng Pek \\ Department of Mechanical Engineering, National Cheng Kung University, Tainan 701, Taiwan \\ * Correspondence: scshi@mail.ncku.edu.tw; Tel.: +886-6-2757575 (ext. 62176); Fax: +886-6-2352973
}

Received: 30 July 2019; Accepted: 9 September 2019; Published: 10 September 2019

Featured Application: The green tribology film is ideal for use in low-load environments, such as anti-wear layers on electronic printed circuit boards. This film is environmentally friendly and biodegradable. It does not cause damage to the environment before or after use and is representative of the next generation of environmentally friendly films.

\begin{abstract}
Green tribology film comprising hydroxypropyl methylcellulose modified with nanoparticles and molybdenum disulfide was prepared by the solvent evaporation method. The nanoparticle additives were $\mathrm{Al}, \mathrm{Cu}, \mathrm{Al}_{2} \mathrm{O}_{3}$, and $\mathrm{CuO}$. The tribological behavior of nanoparticles and $\mathrm{MoS}_{2}$ was investigated using a ball-on-disk tribometer. The surface morphologies and worn surfaces were observed through scanning electron microscopy. The preferred orientation and crystallographic structure of $\mathrm{MoS}_{2}$ and nanoparticles in the composites were studied via X-ray diffraction. Energy-dispersive X-ray spectroscopy was used to analyze the transfer film formed on the counterball. The surface profile, wear depth, wear width, and wear volume were studied by a $3 \mathrm{D}$ optical profiler. The synergistic effect of micro-platelet $\mathrm{MoS}_{2}$ and nanoparticles contributed to the excellent wear resistances. It was found that the wear volume of hydroxypropyl methylcellulose (HPMC)/MoS 2 composites decreased dramatically when $\mathrm{Al}, \mathrm{Cu}$, and $\mathrm{CuO}$ were used as fillers, and it decreased slightly with $\mathrm{Al}_{2} \mathrm{O}_{3}$. The optimal wear resistance was obtained with $3 \mathrm{wt} . \%$ additives. These filled composites had a lower coefficient of friction lower than that of unfilled HPMC/MoS 2 . The optimal result was observed for the $\mathrm{HPMC} / \mathrm{MoS}_{2} / \mathrm{CuO} 3 \mathrm{wt} . \%$ composite coating, which reduces the wear and friction coefficient by $90 \%$ and $84 \%$, respectively, as compared to coatings without additives. Nanoparticles existed in the wear track as the third particles improved the load capacity of the composites. The wear mechanism of the composites is discussed in terms of the worn surfaces and the analysis of transfer film with a third-body approach. The dissipation energy theory is used to evaluate the dominant wear mechanism of the system.
\end{abstract}

Keywords: third body; dissipation energy; tribology; hydroxypropyl methylcellulose (HPMC); additive; green material

\section{Introduction}

The main concept of tribology is to "control friction, reduce wear, and improve lubrication". Green tribology is a new approach in the scientific community that emphasizes on the development of wear technology from the perspective of ecological balance and environmental protection. The primary objective of green tribology is to improve quality of life and reduce energy consumption, carbon dioxide emissions, and environmental costs [1]. Nosonovsky and Bhusan mentioned that green tribology can be divided into two major areas: Green engineering and green chemistry. Green engineering involves reducing the generation of pollutants and the harm to human living environment while ensuring that 
the industry is technically feasible. Green chemistry involves the use of hazardous substances for the production of chemical products [2].

In the field of green chemistry, many scientists use various plant extracts, tea, coffee, bananas, amino acids, glucose, and other natural derivatives as a reductant and capping agent in the synthesis process to be environmentally friendly. The green production methods for silver, gold, iron, oxide, salt, etc. on the nanometer scale are widely discussed topics [3]. Among them, some scholars used dried eucalyptus leaching solution to prepare nano-silver particles in a continuous flow tubular microreactor [4].

Lubricants play an important role in the world's economic and industrial development. In the past few centuries, the main raw material for lubricating oil has been petroleum. To promote green tribology, biodegradable vegetable oil can effectively limit environmental pollution, and vegetable oil also has the advantages of viscosity, high lubricity, and low volatility.

To improve the anti-wear effect of vegetable oils, many researchers have added other additives, such as nanoparticles [5], copolymers, and cellulose [6], to improve the properties of vegetable oils. Biopolymer-based composite coatings can also be used as the main raw material for the paper and packaging industries. Many scholars continue to explore available biomaterials and test their gas barrier and moisture barrier properties [7].

Hydroxypropyl methylcellulose (HPMC) was made by utilizing natural cellulose, such as cotton linters, as a raw material. The raw material was immersed in an alkali solution to deprotonate a hydroxyl group to form an alkoxy anion, and then a methyl chloride was added to propylene oxide to induce a condensation reaction that synthesized a nonionic cellulose ether. The chemical structure can be viewed in Shi's research [8]. Owing to the hydrophilicity and superior swellability of HPMC, it is used as a carrier material for oral drugs [9]. When an oral drug is contacted with water or a biological fluid, the fluid diffuses into the device, causing the polymer chain to relax and the volume to expand, which in turn makes the drug diffuse out of the device with a controlled release rate. HPMC is also used as a food packaging material. Scientific researchers will be able to consume chitosan, tripolyphosphate, and other non-toxic nanoparticles to enhance the mechanical properties and barrier properties of HPMC coating [10,11].

Fahs added stearic acid to HPMC because of its hydrophobic nature to reduce the surface roughness and surface energy of the film, effectively reducing the friction coefficient and adhesion and preparing a film with anti-wear properties [12]. Shi prepared a HPMC coating on a silicon substrate with the best ratio of water and HPMC (5\% HPMC and $30 \mathrm{~mL}$ water) to reduce the friction and anti-wear behavior [13], and he used Raman spectroscopy to observe the transfer layer formed in the wear [14]. In addition, in a toxicity test of zebrafish, Shi also found that HPMC has excellent solubility and compatibility as well as the potential for use as a green grinding material [15]. Huang found that HPMC has self-repairing properties. The wear scars produced by HPMC after the abrasion test can be refilled with HPMC solution, or condensed water can be filled by high temperature and high humidity treatment $[16,17]$. To increase the anti-wear effects of HPMC, Wu added molybdenum disulfide $\left(\mathrm{MoS}_{2}\right)$ additive to HPMC and successfully prepared a $\mathrm{MoS}_{2} / \mathrm{HPMC}$ composite coating with controlled thickness. Raman, FTIR, and X-ray diffractometers were used for the composite analysis $[8,18]$. Solid lubricant $\mathrm{MoS}_{2}$ was found to form a transfer layer during the abrasion process, providing lubrication and prolonging the life of the composite coating [15,19-22].

There have been many references to the study that additives can increase the tribology properties of HPMC films. However, studies on how additives add to the tribology characteristics and the wear mechanism have not yet been conducted. This paper introduces the third-body concept, taking the microscopic observation of the wear area as evidence and proposes the influence of the third-body mechanism on the tribology behavior of HPMC composites. This is helpful for the study of wear resistance behavior and practical application of subsequent additives. 


\section{Materials and Experiment}

\subsection{Preparation of HPMC Composites}

HPMC (606, Shin Etsu, Osaka, Japan) was used as the base material. Molybdenum disulfide powder (grain size: $2 \mu \mathrm{m}$ ) was commercially obtained from Sigma-Aldrich Corporation (USA). The nano- $\mathrm{Al}$, nano- $\mathrm{Cu}$, nano- $\mathrm{Al}_{2} \mathrm{O}_{3}$, nano-CuO were obtained from Yi-Mei Company (New Taipei City, Taiwan). The HPMC solution and $\mathrm{MoS}_{2}$ were mixed in the solution with ultrasonic treatment. Preparation parameters of HPMC-based composite solution was listed in Table 1. Nanoparticles were dissolved in ethanol. The nanoparticle solution and the $\mathrm{HPMC} / \mathrm{MoS}_{2}$ solution were mixed using a magnetic stirrer. After that, $486 \mu \mathrm{L}$ of the mixed solution was dripped onto the glass substrate via microtubule titration. The films were prepared in a controlled environment chamber at a temperature of $25 \pm 2{ }^{\circ} \mathrm{C}$ and relative humidity of $45 \pm 5 \%$ for $6 \mathrm{~h}$ to form a composite coating. The thickness of all coatings was maintained at $75 \pm 5 \mu \mathrm{m}$ (observed by 3D laser scanning microscope, VK 9700, Keyence, Osaka, Japan). Four types of composite coatings were prepared, and each composite coating had three different additive ratios (1, 2, and $3 \mathrm{wt} . \%)$. Surface roughness (Ra) of HPMC/MoS $2 /$ nano-particles was listed in Table 2.

Table 1. Preparation parameters of hydroxypropyl methylcellulose (HPMC)-based composite solution.

\begin{tabular}{ccccc}
\hline \multirow{2}{*}{ Solution Type } & \multicolumn{2}{c}{ Weight of Solute (g) } & \multicolumn{2}{c}{ Weight of Solvent (g) } \\
\cline { 2 - 5 } & HPMC & $\mathbf{M o S}_{\mathbf{2}}$ & DI Water & Ethanol \\
\hline HPMC/MoS & \multicolumn{2}{c}{0.5} & 1.8 & 7.2 \\
\hline \multicolumn{5}{c}{ HPMC/MoS $_{2} /$ nanoparticle solution } \\
\hline Solution type & Nanoparticle (g) & Ethanol (g) & Span80 (g) & HPMC/MoS $_{2}(\mathrm{~g})$ \\
\hline 1 wt.\% & 0.2 & 9.2 & 0.1 & 10.5 \\
2 wt.\% & 0.4 & 8.9 & 0.2 & 10.5 \\
3 wt.\% & 0.6 & 8.6 & 0.3 & 10.5 \\
\hline
\end{tabular}

Table 2. Surface roughness (Ra) of HPMC/MoS2/nano-particles.

\begin{tabular}{|c|c|c|c|c|}
\hline \multirow[b]{2}{*}{ Nanoparticle (NP) } & \multicolumn{4}{|c|}{ Surface Roughness, Ra $(\mu \mathrm{m})$} \\
\hline & 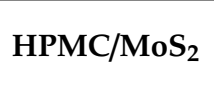 & $\begin{array}{c}\mathrm{HPMC} / \mathrm{MoS}_{2} / \mathrm{NP} \\
1 \text { wt. } \%\end{array}$ & $\begin{array}{c}\mathrm{HPMC} \mathrm{MoS}_{2} / \mathrm{NP} \\
2 \mathrm{wt.} \%\end{array}$ & $\begin{array}{c}\mathrm{HPMC} \mathrm{MoS}_{2} / \mathrm{NP} \\
3 \mathrm{wt.} \%\end{array}$ \\
\hline $\mathrm{Al}$ & \multirow{4}{*}{$1.96 \pm 0.01$} & $2.12 \pm 0.04$ & $2.35 \pm 0.05$ & $2.45 \pm 0.11$ \\
\hline $\mathrm{Cu}$ & & $2.19 \pm 0.15$ & $2.11 \pm 0.07$ & $2.63 \pm 0.19$ \\
\hline $\mathrm{Al}_{2} \mathrm{O}_{3}$ & & $2.27 \pm 0.01$ & $1.61 \pm 0.13$ & $1.66 \pm 0.16$ \\
\hline $\mathrm{CuO}$ & & $2.14 \pm 0.09$ & $2.13 \pm 0.07$ & $2.24 \pm 0.01$ \\
\hline
\end{tabular}

\subsection{Friction and Wear Tests}

The friction and wear tests were conducted using a ball-on-disk tribometer. An AISI 52100 steel counterball with a diameter of $6.31 \mathrm{~mm}$ was used for the friction test. Steel-modified HPMC composite coatings were selected as the tribological pairs. Under a normal load of $2 \mathrm{~N}$, the counterball was slid for 5,50 , and $100 \mathrm{~m}$, at a sliding velocity of $0.03 \mathrm{~m} / \mathrm{s}$, with a sliding distance (one cycle) of $6.38 \mathrm{~mm}$ under the dry sliding condition. For each experimental condition, three tests were performed, and the average result was reported. The wear volume of the composites was measured using a Keyence 3D optical profiler. The worn surfaces of the composites were observed on Hitachi SU-5000 scanning electron microscopy. 


\section{Results and Discussion}

\subsection{Observation of HPMC Composites}

The nanoparticle shape is shown in Figure 1. The size distribution of the additive is $50-300 \mathrm{~nm}$, and some of the larger particles may be caused by aggregation. Therefore, when studying the effect of nano-additives on the tribology characteristics, the size factor can be eliminated.

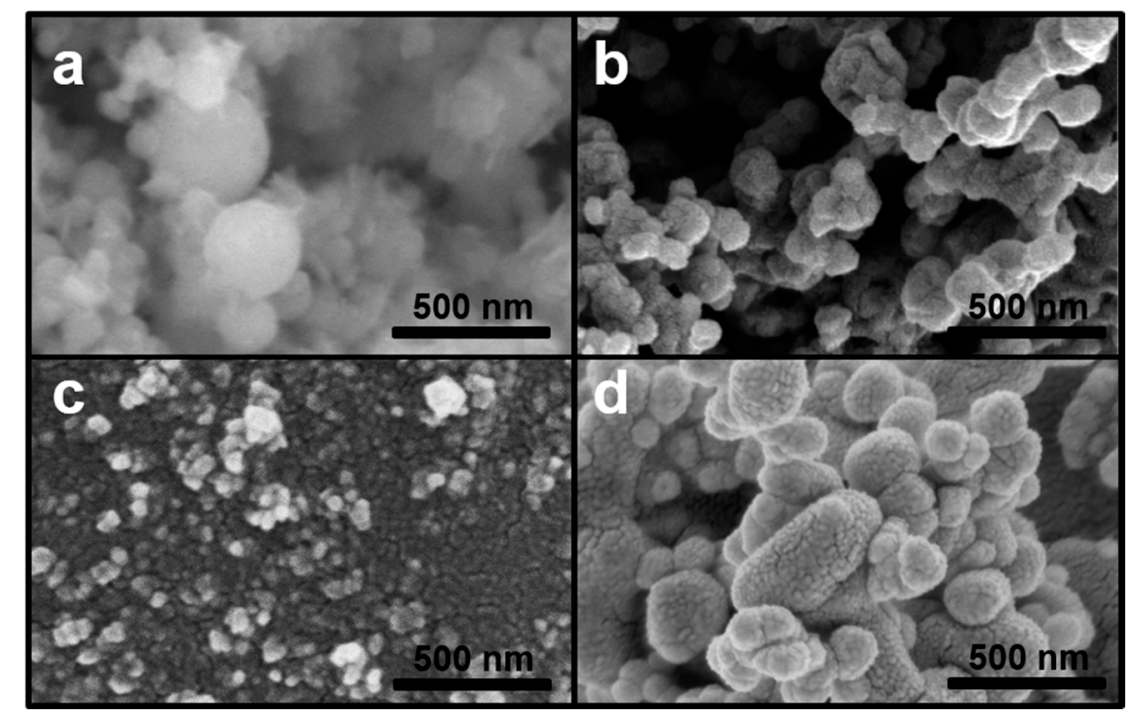

Figure 1. Scanning electron microscope observation of nanoparticles: (a) $\mathrm{Al}$, (b) $\mathrm{Cu},(\mathbf{c}) \mathrm{Al}_{2} \mathrm{O}_{3}$, and $(\mathbf{d}) \mathrm{CuO}$.

The surface observations of HPMC/additive composite coating for various concentrations are shown in Figures 2-5, which are $\mathrm{HPMC} / \mathrm{MoS}_{2} / \mathrm{Al}, \mathrm{HPMC} / \mathrm{MoS}_{2} / \mathrm{Cu}, \mathrm{HPMC} / \mathrm{MoS}_{2} / \mathrm{Al}_{2} \mathrm{O}_{3}$, $\mathrm{HPMC} / \mathrm{MoS}_{2} / \mathrm{CuO}$, respectively. For the $\mathrm{HPMC} / \mathrm{MoS}_{2}$ coating, layered molybdenum disulfide particles are uniformly distributed in the composite coating and demonstrate good compatibility with HPMC. When the additive is added into $\mathrm{HPMC} / \mathrm{MoS}_{2}$, nanoparticle aggregation can be decreased by the good dispersion ability of the HPMC solution. The scanning electron microscope (SEM) observation of the surface of the nanocomposite coating shows that molybdenum disulfide is mainly encapsulated in the HPMC matrix while the nanoparticle is presented on the surface and covers a larger surface area.

From the morphology of the HPMC/MoS $/ \mathrm{Al}$ composite coating, as shown in Figure 2, it is demonstrated that more nanoparticles are densely distributed in the composite coating as the number of additives increases. At high-magnification SEM observation, the aggregation of the particles was not obvious, and the size of the additive was maintained at nanometer size. The surface of $\mathrm{HPMC} / \mathrm{MoS}_{2} / \mathrm{Cu}$ composite coating has fewer particles, and the copper particles are uniformly dispersed in the composite coating, as shown in Figure 3. The nanoparticles on the surface of the HPMC/MoS $/ 212 \mathrm{O} 3$ composite coating have agglomerated and form larger particles as the content increases, as shown in Figure 4. The number of nanoparticles observed on the surface of the $\mathrm{HPMC} / \mathrm{MoS}_{2} / \mathrm{CuO}$ composite coating was the lowest at the same observation scale owing to the highest density of $\mathrm{CuO}$, as shown in Figure 5. Nano-aluminum and nano-alumina particles having lower density are less likely to sink and have a larger number of particles for the same number of grams owing to their light weight and small bulk density. Nano-copper and nano-copper oxide particles have higher density, and the particles tend to precipitate; thus, fewer particles are observed on the surface. 


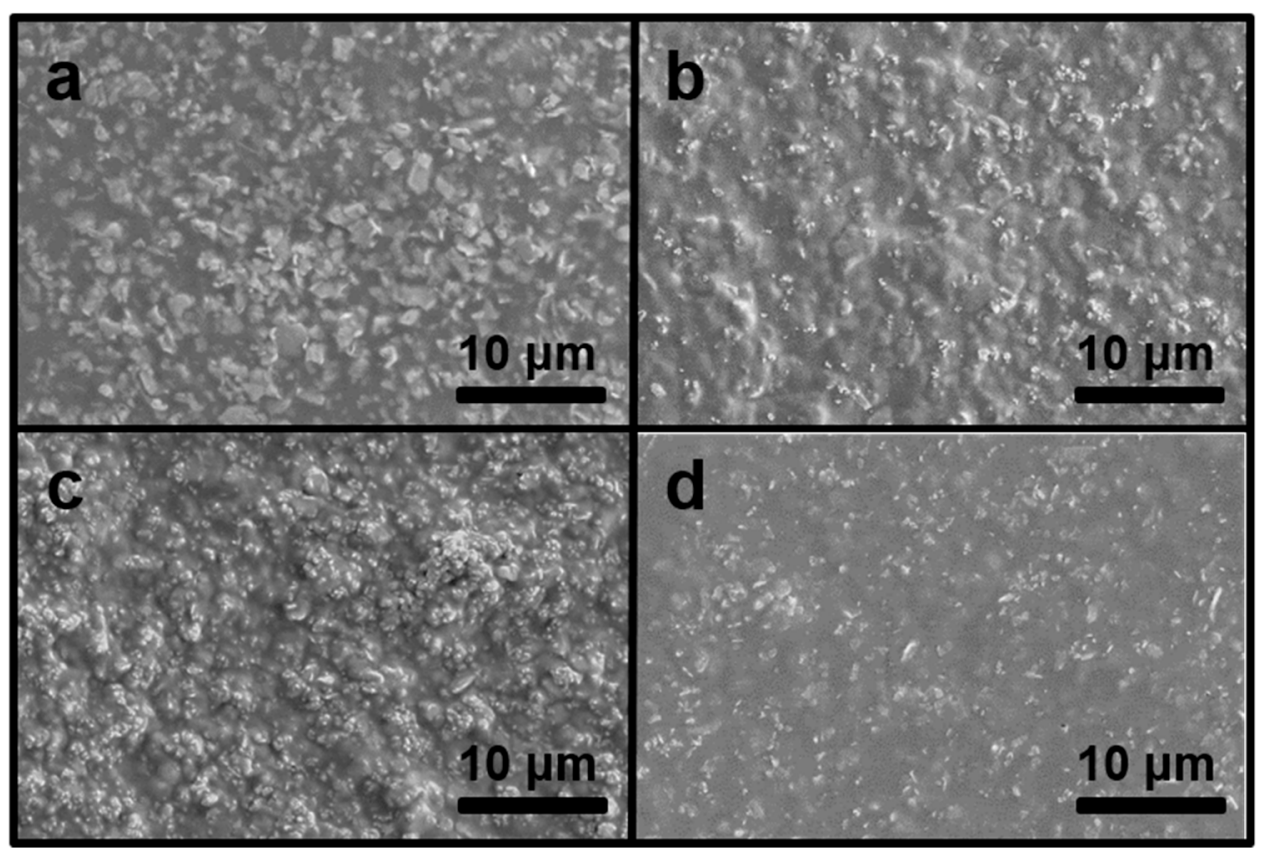

Figure 2. SEM observation of HPMC/MoS $2 / \mathrm{Al}$ composites: (a) HPMC/MoS 2 , (b) Al 1 wt.\%, (c) Al 2 wt.\%, and (d) Al 3 wt.\%.

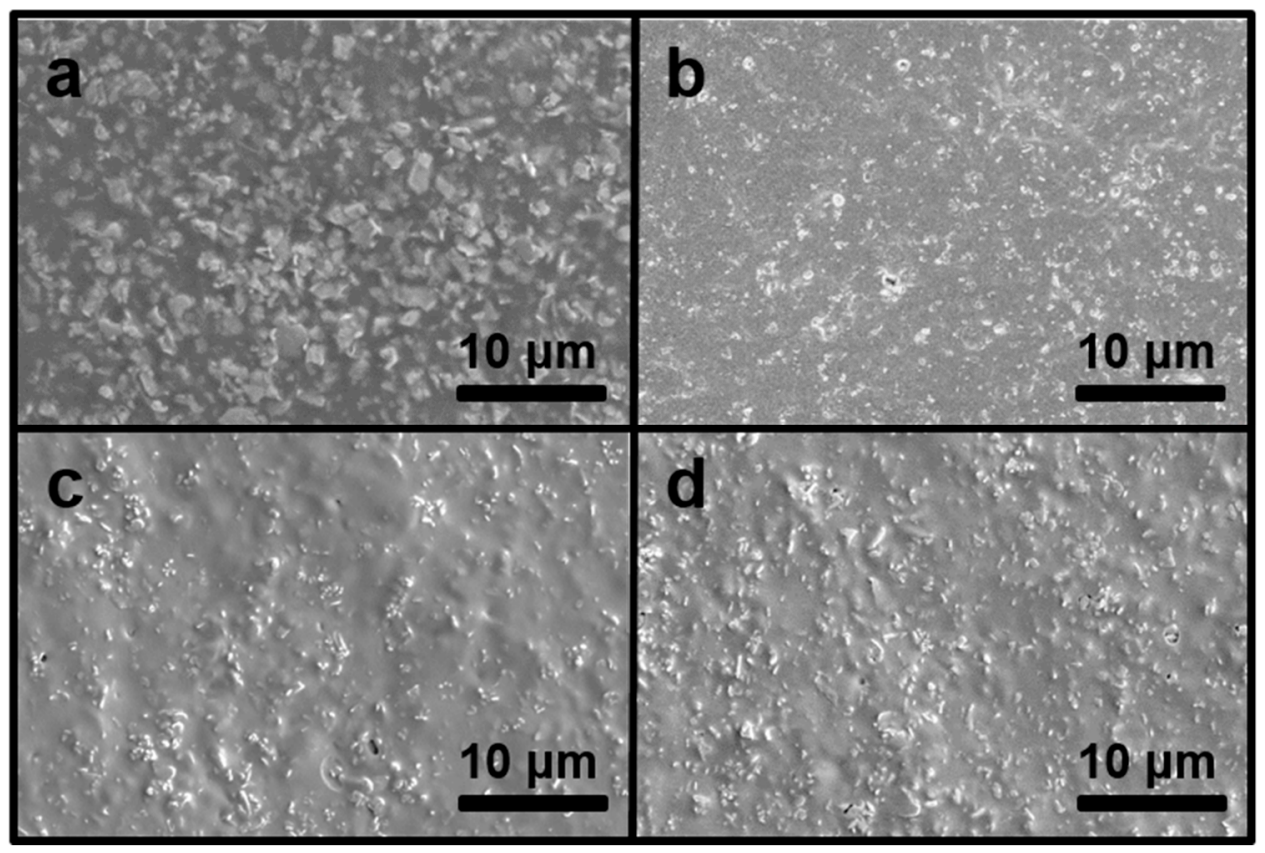

Figure 3. SEM observation of HPMC/MoS $/ \mathrm{Cu}$ composites: (a) $\mathrm{HPMC} / \mathrm{MoS}_{2}$, (b) $\mathrm{Cu} 1$ wt.\%, (c) Cu 2 wt. $\%$, and (d) Cu 3 wt.\%. 


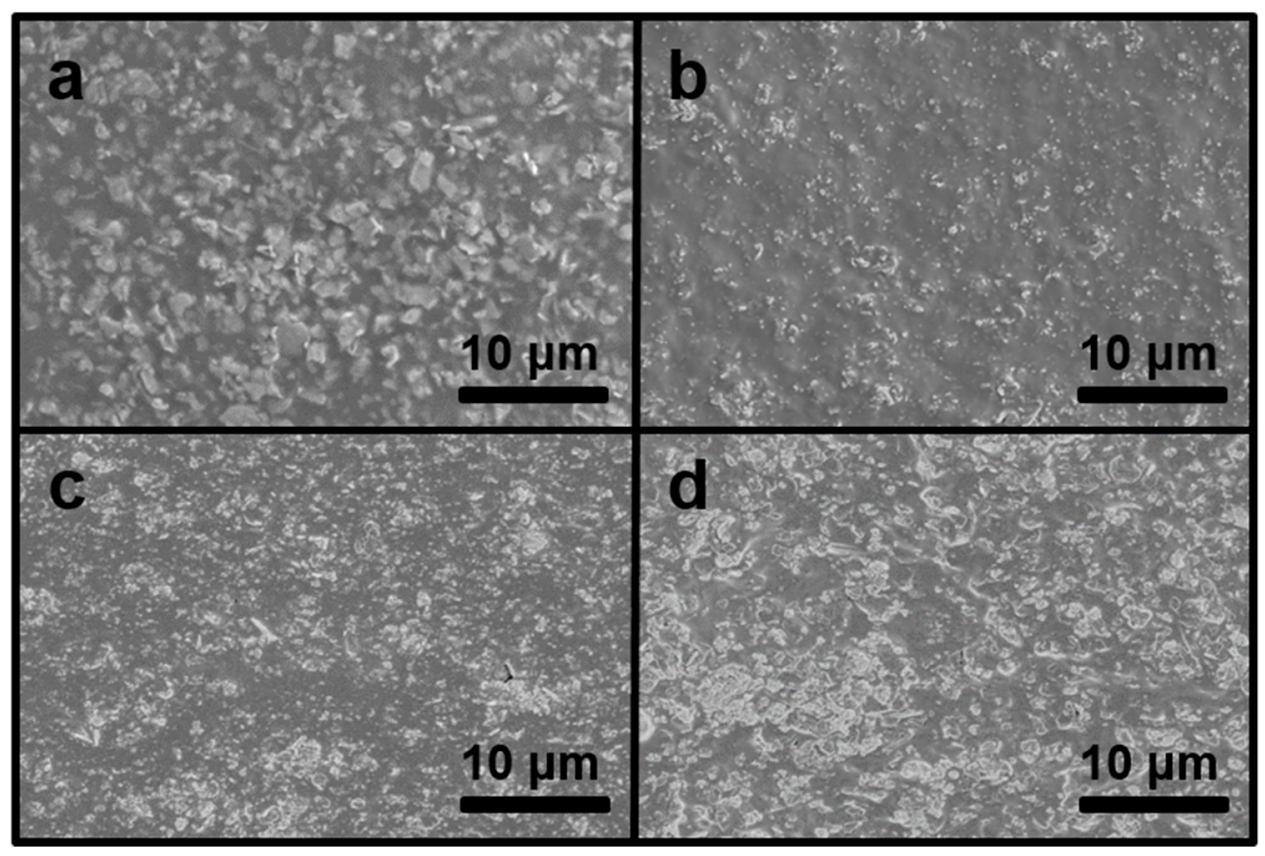

Figure 4. SEM observation of $\mathrm{HPMC} / \mathrm{MoS}_{2} / \mathrm{Al}_{2} \mathrm{O}_{3}$ composites: (a) HPMC/MoS ${ }_{2}$, (b) $\mathrm{Al}_{2} \mathrm{O}_{3} 1$ wt. $\%$, (c) $\mathrm{Al}_{2} \mathrm{O}_{3} 2$ wt. $\%$, and (d) $\mathrm{Al}_{2} \mathrm{O}_{3} 3$ wt. $\%$.

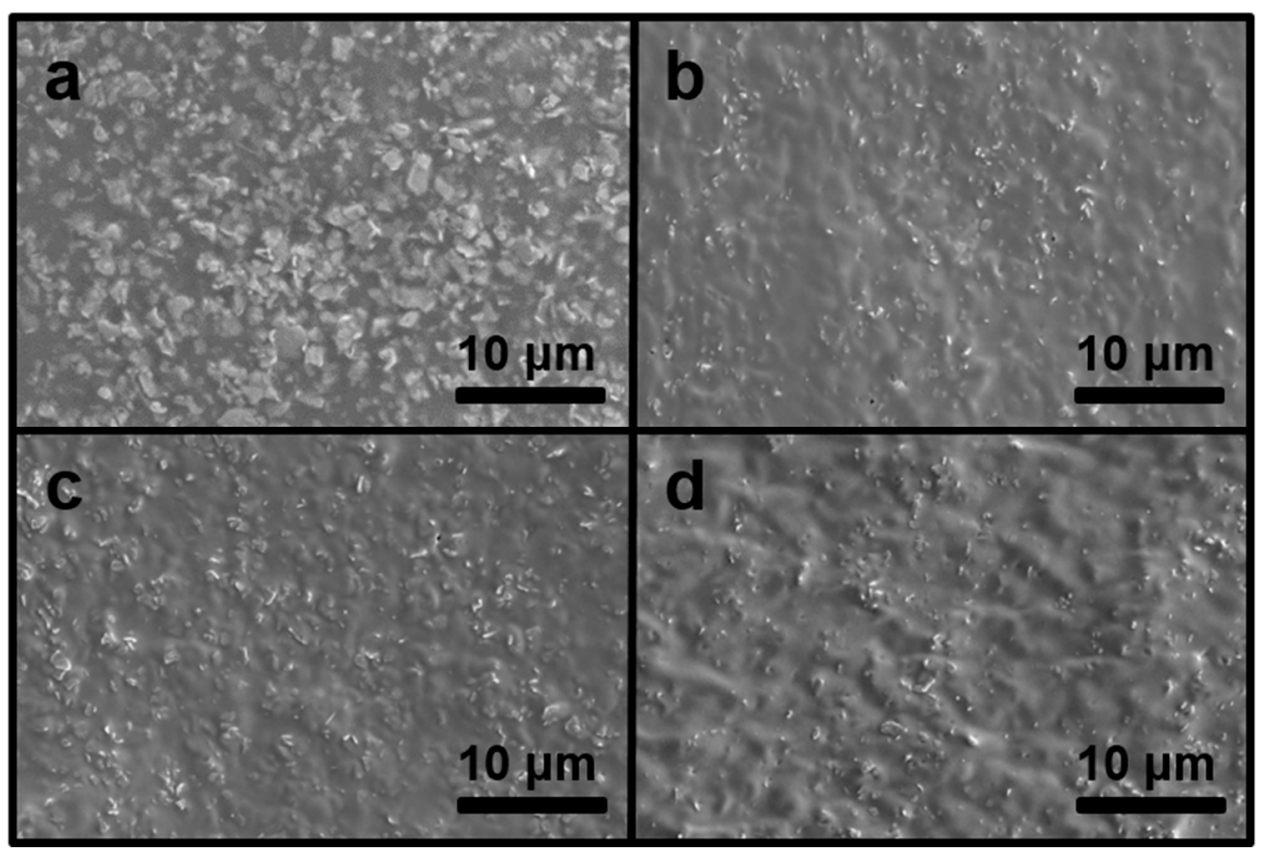

Figure 5. SEM observation of $\mathrm{HPMC} / \mathrm{MoS}_{2} / \mathrm{CuO}$ composites: (a) $\mathrm{HPMC} / \mathrm{MoS}_{2}$, (b) $\mathrm{CuO} 1$ wt.\%, (c) $\mathrm{CuO}$ 2 wt. \%, and (d) $\mathrm{CuO} 3$ wt. $\%$.

\subsection{Friction and Wear Properties of the HPMC Composites}

The effect of nanoparticles on the friction coefficient of $\mathrm{HPMC} / \mathrm{MoS}_{2} /$ additive composites is shown in Figure 6. The HPMC/MoS 2 /additive composites exhibited a lower friction coefficient compared to the $\mathrm{HPMC} / \mathrm{MoS}_{2}$ coating, revealing that the addition of nanoparticles can effectively improve the tribology property of the composite. The addition of the metal particles, $\mathrm{Al}$ and $\mathrm{Cu}$, is effective in reducing the coefficient of friction (COF), and the COF continuously decreases with an increase in the metal particle concentration. The oxide additives, $\mathrm{Al}_{2} \mathrm{O}_{3}$ and $\mathrm{CuO}$, can achieve a lower $\mathrm{COF}$ relative to 
the metal additive, and the $\mathrm{COF}$ reaches a stable state after adding the oxide additive. The lowest $\mathrm{COF}$ in this study was obtained by $\mathrm{HPMC} / \mathrm{MoS}_{2} / \mathrm{CuO} 2$ and $3 \mathrm{wt} . \%$.

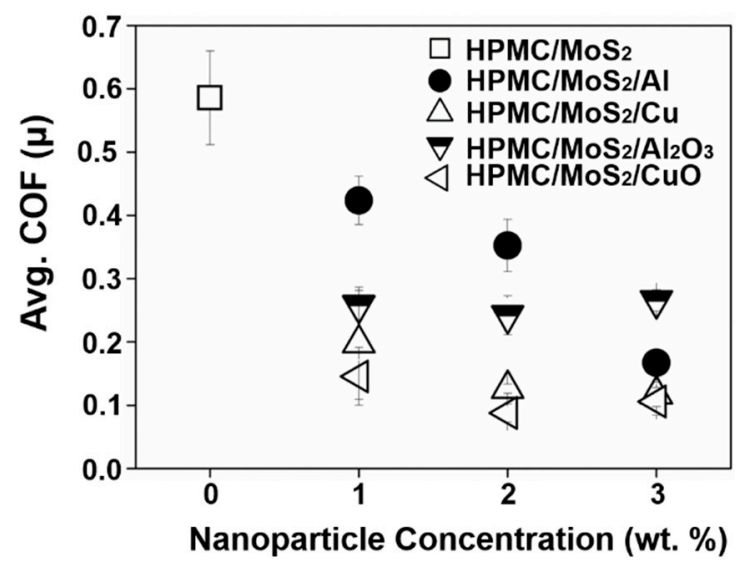

Figure 6. Average coefficient of friction of the $\mathrm{HPMC} / \mathrm{MoS}_{2} /$ additive composites (sliding distance $100 \mathrm{~m})$.

The wear volume of HPMC/MoS $/$ additive composites is shown in Figure 7. Nano-additives can effectively reduce the wear volume of the coating, except for the higher alumina additive concentration group. The addition of high concentration of alumina may cause embrittlement of the composite film, resulting in an increase in the wear volume. On comparing all additives, HPMC/MoS $2 / \mathrm{CuO} 2 \mathrm{wt} . \%$ was observed to have the best wear-reducing ability, for which $90 \%$ reduction of wear rate can be achieved compared to the HPMC/MoS 2 coating.

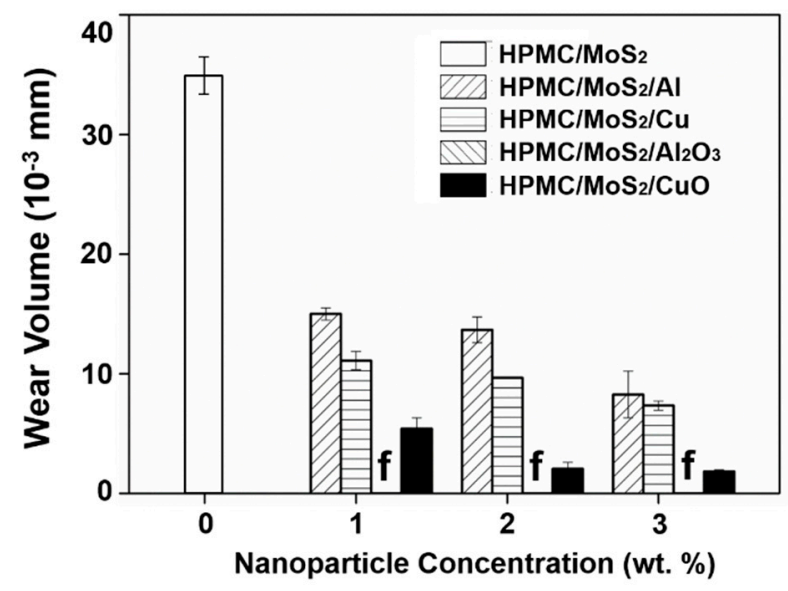

Figure 7. Wear volume of the $\mathrm{HPMC} / \mathrm{MoS}_{2} /$ additive composites (sliding distance $100 \mathrm{~m}$ ). f represents the failure of the coating.

The worn surfaces of the HPMC/MoS 2 and $\mathrm{HPMC} / \mathrm{MoS}_{2} /$ additive $2 \mathrm{wt} . \%$ composites coating after tribology test $(50 \mathrm{~m})$ are shown in Figure 8. Plucking and ploughing marks can be observed for the HPMC/MoS 2 coating. Slight scuffing was observed on the HPMC/MoS $/$ Al composite. The worn surface of $\mathrm{HPMC} / \mathrm{MoS}_{2} / \mathrm{Cu}$ was smoother than the others; however, it still had wear marks. Thus, the nanoparticles agglomerated in the wear scar on the HPMC/MoS $2 / \mathrm{Al}_{2} \mathrm{O}_{3}$ composite, which caused abrasive wear. Further, fine wear debris stacked on the surface of the $\mathrm{HPMC} / \mathrm{MoS}_{2} / \mathrm{CuO}$ composite. $\mathrm{CuO}$ particles are accumulated on the surface because of the abrasion. These hard particles appear on the surface of the coating and they provide good load capacity and anti-wear behavior. 


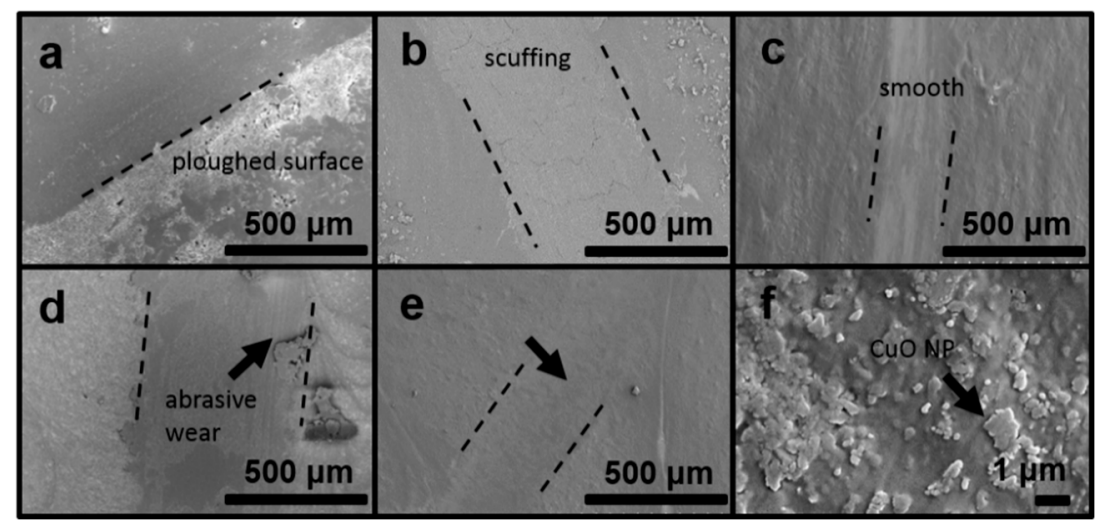

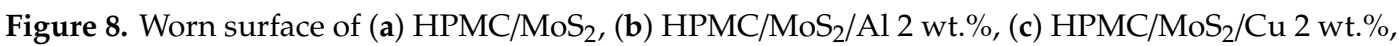
(d) $\mathrm{HPMC} / \mathrm{MoS}_{2} / \mathrm{Al}_{2} \mathrm{O}_{3} 2$ wt.\%, (e) $\mathrm{HPMC} / \mathrm{MoS}_{2} / \mathrm{CuO} 2 \mathrm{wt}$ \% ; (f) enlarged arrow indicates the place in (e) (sliding distance $50 \mathrm{~m}$ ).

In the previous results (Figures 6-8), the $\mathrm{HPMC} / \mathrm{MoS}_{2} / \mathrm{CuO}$ composites showed good wear resistance and COF reduction behavior. Therefore, a long-distance wear test (1000 $\mathrm{m})$ was performed to study the tribology mechanism of the composite coating.

The wear surface of the substrate and the counter ball is shown in Figure 9. The transfer film on the substrate and the counter ball is the third-body layer formed by abrasion, and it is evident in Figure $9 \mathrm{a}, \mathrm{b}$. Thus, owing to the synergistic effect of $\mathrm{MoS}_{2}$ and $\mathrm{CuO}$ nanoparticles, a thin transfer film was formed, and it helped minimize the friction effect between the substrate and the grinding ball.

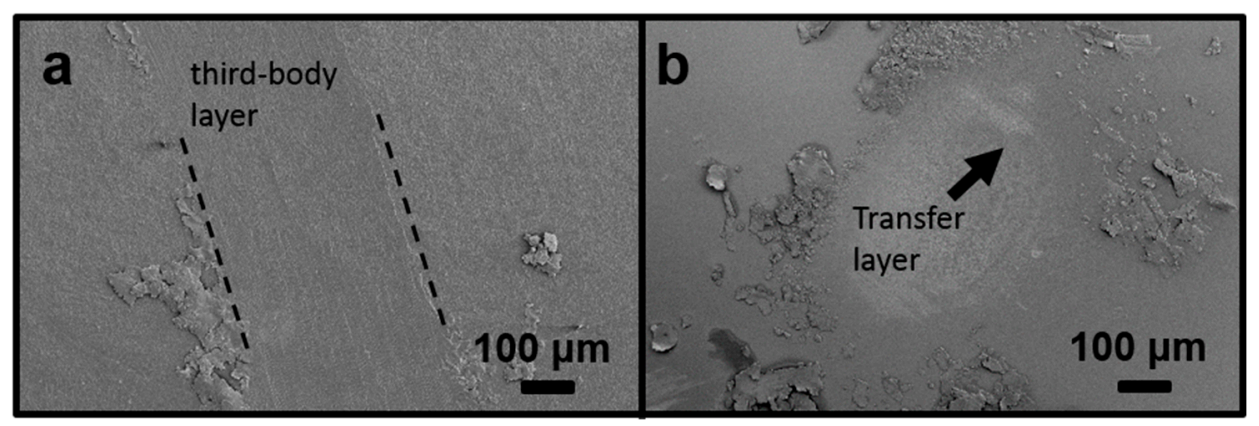

Figure 9. (a) Third-body film (b) transfer film on the steel ball.

\subsection{Dissipation Energy Analysis of the HPMC Composites}

Surface friction is directly related to dissipated energy, and the form of wear changes the material structure. Sliding wear models can be used to illustrate the dissipated energy of the system. The volume of material removed by sliding wear is directly proportional to the work done due to friction [23]. The slope in the graph of volume of material removed vs. friction work represents the dominant wear mechanism. The Archard wear model, which is a model used to describe sliding wear, is given below:

$$
\begin{aligned}
\Delta \mathrm{E} & =\bar{F} \times V \times \Delta t \\
\mathrm{E} & =\sum \Delta \mathrm{E} \\
\bar{F} & =\mu N
\end{aligned}
$$

where $\bar{F}$ is the average value of the friction force, $V$ is the constant sliding speed, and $\Delta t$ is the time interval.

Figure 10 shows the wear volume and dissipation energy curves for the composites. The figure shows three groups of slopes, it can be inferred that each composite exhibited different wear mechanism 
under wear test. In this regard, to compare the difference between slopes, the wear mechanism of $\mathrm{HPMC} / \mathrm{MoS}_{2} /$ additives is similar. However, for an intestine HPMC coating, the wear is more extensive, indicating that each unit of dissipated energy caused a greater wear volume. The $\mathrm{MoS}_{2}$ additive had a pronounced positive effect on the tribological properties of the composite. Furthermore, the effect of metal and metal oxide additives on the tribology characteristics is compared. Metal oxide has a higher hardness with respect to the metal particles; it can provide a better load capacity, and therefore has better tribology characteristics.

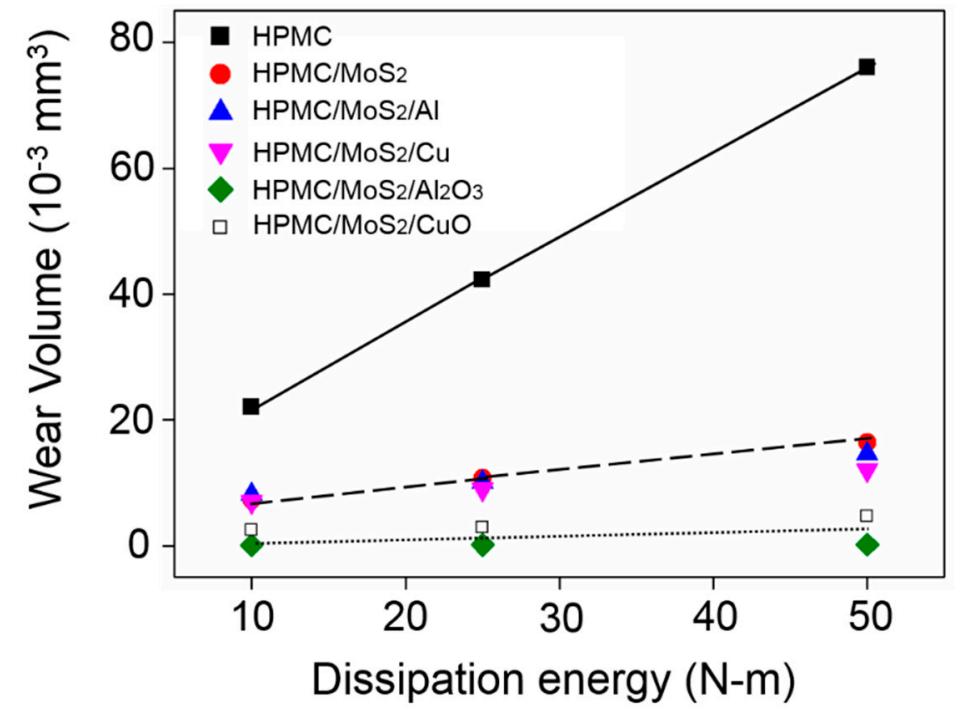

Figure 10. Wear volume and dissipation energy curves of HPMC-based composites ( $2 \mathrm{wt} . \%$ additive).

\section{Conclusions}

Based on the analyses described and results discussed in the previous sections, the following conclusions can be derived. Nanoparticles disperse well in HPMC and exhibit good film-forming properties. The addition of nanoparticles avoids the ploughing effect and decreases the friction coefficient and wear volume. The delamination of $\mathrm{MoS}_{2}$ was facilitated by shear force, which resulted in good flowability. The wettability of $\mathrm{MoS}_{2}$ helps the formation of the transfer film; when nanoparticles stack in wear scar, they can transfer loading and accommodate velocity as third bodies. The plastic deformation in the metallic-nanoparticles-filled composites leads to shear behavior. Metallic oxide nanoparticles have similar hardness to ceramic particles. Therefore, composites filled with metallic oxide nanoparticles provide better load-bearing capacity and exhibit better anti-wear and lubricating behaviors. Considering the example of metal additives, the wear volume can be reduced by a minimum of $50 \%$. In the case of $\mathrm{CuO}$, which was the best additive, it was possible to reduce the wear and friction coefficient by $90 \%$ and $84 \%$, respectively. As a result of this work, the major new contributions to understanding the third-body layer and wear mechanism of the green tribology film are as follows:

(1) $\mathrm{MoS}_{2}$ additive is beneficial for the formation of third-body layer, which is the main factor of improving tribology property of the composite.

(2) In the dissipation energy observation, different slopes represent different wear mechanism. The lower the slope, more lubricating factors are involved in the wear process. The dissipation energy analysis can be used as a simple method to determine wear mechanisms in the wear system.

Author Contributions: S.-C.S. and S.-S.P. conceived and designed the experiments; S.-C.S. and S.-S.P. performed the experiments; S.-C.S. and S.-S.P. analyzed the data; S.-C.S. contributed reagents/materials/analysis tools; S.-C.S. and S.-S.P. wrote the paper.

Funding: The authors gratefully acknowledge the financial supports for this project from the Ministry of Science and Technology in Taiwan (106-2221-E-006 -092 -MY3). 
Acknowledgments: The authors also thank the Center for Micro/Nano Science and Technology and Instrument Center, National Cheng Kung University (NCKU), and Everlight Electronics Co., Ltd. (New Taipei City, Taiwan), for technical support.

Conflicts of Interest: The authors declare no conflict of interest.

\section{References}

1. Zhang, S.W. Green tribology: Fundamentals and future development. Friction 2013, 1, 186-194. [CrossRef]

2. Nosonovsky, M.; Bhushan, B. Green Tribology: Principles, research areas and challenges. Philos. Trans. $R$ Soc. A 2010, 368, 4677-4694. [CrossRef] [PubMed]

3. Kharissova, O.V.; Dias, H.R.; Kharisov, B.I.; Pérez, B.O.; Pérez, V.M.J. The greener synthesis of nanoparticles. Trends Biotechnol. 2013, 31, 240-248. [CrossRef] [PubMed]

4. Kaviya, S.; Santhanalakshmi, J.; Viswanathan, B. Green synthesis of silver nanoparticles using Polyalthia longifolia leaf extract along with D-sorbitol: Study of antibacterial activity. J. Nanotechnol. 2011, 2011, 152970. [CrossRef] [PubMed]

5. Alves, S.M.; Barros, B.S.; Trajano, M.F.; Ribeiro, K.S.B.; Moura, E. Tribological behavior of vegetable oil-based lubricants with nanoparticles of oxides in boundary lubrication conditions. Tribol. Int. 2013, 65, 28-36. [CrossRef]

6. Quinchia, L.A.; Delgado, M.A.; Reddyhoff, T.; Gallegos, C.; Spikes, H.A. Tribological studies of potential vegetable oil-based lubricants containing environmentally friendly viscosity modifiers. Tribol. Int. 2014, 69, 110-117. [CrossRef]

7. Rastogi, V.; Samyn, P. Bio-based coatings for paper applications. Coatings 2015, 5, 887-930. [CrossRef]

8. Shi, S.C.; Huang, T.F. Raman study of HPMC biopolymer transfer layer formation under tribology test. Opt. Quantum Electron. 2016, 48, 532. [CrossRef]

9. Siepmann, J.; Peppas, N.A. Modeling of drug release from delivery systems based on hydroxypropyl methylcellulose (HPMC). Adv. Drug Deliv. Rev. 2012, 64, 163-174. [CrossRef]

10. de Moura, M.R.; Aouada, F.A.; Avena-Bustillos, R.J.; McHugh, T.H.; Krochta, J.M.; Mattoso, L.H. Improved barrier and mechanical properties of novel hydroxypropyl methylcellulose edible films with chitosan/tripolyphosphate nanoparticles. J. Food Eng. 2009, 92, 448-453. [CrossRef]

11. Shi, S.C.; Su, C.C. Corrosion inhibition of high speed steel by biopolymer HPMC derivatives. Materials 2016, 9, 612. [CrossRef] [PubMed]

12. Fahs, A.; Brogly, M.; Bistac, S.; Schmitt, M. Hydroxypropyl methylcellulose (HPMC) formulated films: Relevance to adhesion and friction surface properties. Carbohydr. Polym. 2010, 80, 105-114. [CrossRef]

13. Shi, S.C.; Huang, T.F.; Wu, J.Y. Preparation and tribological study of biodegradable lubrication films on Si substrate. Materials 2015, 8, 1738-1751. [CrossRef] [PubMed]

14. Shi, S.C.; Wu, J.Y.; Peng, Y.Q. Transfer layer formation in $\mathrm{MoS}_{2} /$ hydroxypropyl methylcellulose composite. Wear 2018, 408, 208-213. [CrossRef]

15. Shi, S.C. Tribological performance of green lubricant enhanced by sulfidation IF-MoS 2. Materials 2016, 9, 856. [CrossRef] [PubMed]

16. Shi, S.C.; Huang, T.F. Self-healing materials for ecotribology. Materials 2017, 10, 91. [CrossRef] [PubMed]

17. Shi, S.C.; Huang, T.F. Effects of temperature and humidity on self-healing behaviour of biopolymer hydroxylpropyl methylcellulose for ecotribology. Surf. Coat. Technol. 2018, 350, 997-1002. [CrossRef]

18. Shi, S.C.; Wu, J.Y.; Huang, T.F. Raman, FTIR, and XRD study of $\mathrm{MoS}_{2}$ enhanced hydroxypropyl methylcellulose green lubricant. Opt. Quantum Electron. 2018, 48, 474. [CrossRef]

19. Shi, S.C.; Wu, J.Y. Deagglomeration and tribological properties of $\mathrm{MoS}_{2} /$ hydroxypropyl methylcellulose composite thin film. Surf. Coat. Technol. 2018, 350, 1045-1049. [CrossRef]

20. Shi, S.C.; Wu, J.Y. Enhancement mechanism for carbohydrate polymer green lubricant. Polym. Polym. Compos. 2018, 26, 85-90. [CrossRef]

21. Shi, S.C.; Wu, J.Y. Parameter effect on tribology performance of biopolymer composite green lubricant. Sens. Mater. 2017, 29, 1491-1496. 
22. Shi, S.C.; $\mathrm{Wu}$, J.Y. $\mathrm{MoS}_{2}$ additives for enhancing tribological performance of hydroxypropyl methylcellulose biopolymer. Smart Sci. 2017, 5, 167-172. [CrossRef]

23. Ramalho, A.; Miranda, J. The relationship between wear and dissipated energy in sliding systems. Wear 2006, 260, 361-367. [CrossRef]

(C) 2019 by the authors. Licensee MDPI, Basel, Switzerland. This article is an open access article distributed under the terms and conditions of the Creative Commons Attribution (CC BY) license (http://creativecommons.org/licenses/by/4.0/). 